\title{
PARA UMA RELEITURA DA HISTÓRIA CULTURAL DO JAPÃO MODERNO E CONTEMPORÂNEO - OS CONCEITOS DE LITERATURA (bungaku文学) E ARTES (geijutsu 芸術)-
}

Sadami Suzuki

1. Uma rediscussão dos conceitos de "Literatura" (bungaku文学) e “Artes" (geijutsu芸術) a partir de novos questionamentos sobre a conjuntura intelectual (chiteki shisutemu知的システム) da Ásia Oriental Moderna

Atualmente, as questões ambientais têm freado o sistema industrial, que deixa de se voltar exclusivamente para o crescimento produtivo; por outro lado, são inúmeras as questões geradas pelo avanço das ciências naturais, notadamente o da biotecnologia, que envolve diretamente o campo da reprodução humana. $\mathrm{Na}$ esteira dessas polêmicas que requerem ampla discussão, também estão sendo realizadas novas releituras dos valores que formaram o conjunto de conhecimentos que moldaram a Europa moderna. No entanto, os procedimentos a serem adotados para essa releitura não são claros.

Diante disso, como reavaliar esses valores que nortearam o período moderno? Uma das possibilidades encontradas foi desenvolver pesquisas que indagassem sobre a "conjuntura intelectual" (chiteki shisutemu 知的システム) e os "valores" (kachikan 価 值観) que permearam os períodos compreendidos como moderno e contemporâneo na Ásia Oriental. Isso porque o conhecimento advindo da Europa, ao ser introduzido na Ásia Oriental, foi, de acordo com o território ou país, adaptado e moldado conforme a conjuntura intelectual e os "preceitos ou princípios valorativos" (kachikan 価值観) do conjunto de 
valores particulares do pais de recepção. Assim, seria pertinente estudar esses conceitos asiáticos e compará-los aos dos europeus e americanos, levando-se em consideração suas circunstâncias históricas para que desse modo se pudesse relativizar histórica e geograficamente o contexto atribuído ao período moderno.

Quando nos referimos à "conjuntura intelectual" (chiteki shisutemu知的シス テム), estamos nos atendo aos diversos gêneros artísticos de representação cultural e à correlação existente entre eles, isto é, a conjuntura intelectual é a expressão direta de um “sistema conceitual" (gainen no soshiki taisei 概念の組織体制). Podemos igualmente denominá-la de "corpo conceitual" (gainen hensei 概念編成) ou, também, considerar o sistema como uma espécie de "rede de informações" (networkネットワーク).

Podemos citar como exemplo o caso das universidades japonesas que não possuíam a área de Teologia, a qual nas instituições de ensino européias sempre foi considerada uma área fundamental na formação superior. No projeto inicial (Regulamento das universidades japonesas大学規則, 1870), estava prevista a implantação de uma área que corresponderia à da Teologia (na grade curricular compreendia os "Estudos da História da Monarquia Japonesa", o kôgaku皇学, e o “Confucionismo", o jugaku儒学), mas, em 1877, por ocasião da inauguração da Universidade Imperial de Tóquio", essas matérias não foram implantadas). Os "Estudos da História da Monarquia Japonesa" (kôgaku皇学) e os "Estudos Chineses" (kangaku熯学) foram incorporados ao curso de Literatura Japonesa e Chinesa, no Departamento de Literatura Japonesa. Os motivos para que esses estudos passassem a fazer parte do curso de literatura são imprecisos, mas podem estar relacionados ao fracasso da política de nacionalização do ensino centrado nos preceitos xintoístas, ocorrido no início do período Meiji. Somente em 1904 é que o estudo da Religião, que na Europa integrava o Departamento de Teologia, foi implantado na Universidade de Tóquio como área de estudos do Departamento de Filosofia da Faculdade de Humanidades (bunka daigaku文科大学). Esta medida provavelmente está relacionada à diretriz política adotada naquela época (1885) que preconizava que "o xintoísmo é o culto ancestral da casa imperial e, portanto, não se trata de religião" Esta formação das áreas acadêmicas e a diretriz política tiveram o papel fundamental de encaminhar o desenvolvimento das Faculdades de Humanidades do Japão (Ciências Humanas e Sociologia) num rumo totalmente diverso do ocorrido na Europa.

Por outro lado, o fato de a Universidade Imperial de Tóquio, na época de sua inauguração, introduzir o Departamento de Tecnologia foi um fato pioneiro no mundo. $\mathrm{Na}$ Europa e nos Estados Unidos havia a Faculdade de Engenharia (kôgaku工学) e, apesar da supremacia das máquinas a vapor, a tecnologia energética, reconhecida como ciência, passa a fazer parte das Faculdades inserida no Departamento de Ciências como resposta

1. NT. Atual Universidade de Tóquio. 
à necessidade de uma indústria que voltava os olhos para a energia elétrica. No entanto, a distância entre as Ciências e a Engenharia continuava grande e, mesmo adentrando o século $\mathrm{XX}$, ainda não havia o pensamento de agrupar a engenharia civil e as demais num conjunto único que englobasse todas essas engenharias. $O$ fato de a universidade japonesa ter instaurado a Faculdade de Engenharia se deve aos intelectuais da época da Restauração Meiji (1867), que pressentiram o perigo de serem alvos da política ocidental de colonização, assim como pela influência dos oriundos das classes guerreiras, profundamente interessados no poder militar e pela percepção imediata de que estava iminente a época da tecnologia energética; somem-se a isso as condições históricas e culturais do sistema educacional pautado no Neoconfucionismo (shushigaku朱子学), que apregoavam a subordinação de todas as áreas do saber aos desígnios celestiais (tenri 天理). Por outras palavras, ao adotarem a doutrina filosófica do Neoconfucionismo, as classes guerreiras japonesas não tiveram dificuldades de assimilar as Ciências e a Tecnologia européia num só conjunto, sem distingui-las em áreas distintas. Sobre essa postura conciliatória, Sakuma Shôzan (1811 1864), um grande pensador neoconfucionista do final do período xogunal, já havia discorrido num "Documento Oficial de setembro do ano 2 do período Bunshû" (1862). A instituição universitária japonesa, que preteriu a Teologia, mas adotou a Engenharia, transferiu esse padrão educacional para suas colônias Taiwan e Coréia na primeira metade do século XX, quando passou a administrá-las. E, também, por meio do intercâmbio de bolsistas, exportou esse padrão para a China.

O empreendimento de questionar os vários sistemas culturais dos períodos moderno e contemporâneo tem como objetivo promover sua reorganização a partir de um novo modo de orientar o conhecimento. Hoje, no Japão, a baixa natalidade e a globalização estão acelerando não só o processo de reformulação do sistema de ensino médio, mas de todo o sistema educacional de pesquisa a fim de adequá-los às novas necessidades e demandas da população; mas o propósito de reavaliar as bases do conhecimento que expusemos acima pretende ter um alcance maior. $O$ resultado irá fazer abalar o sistema de conhecimento já existente e resultará num movimento de reorganização do sistema universitário e dos grupos de estudo que hoje são subdivididos em várias áreas.

No entanto, organizar os conhecimentos adquiridos ao longo dos anos e transformálos em objeto de pesquisa não é um trabalho fácil e um pesquisador individual sempre se depara com o risco de ver o chão em que pisa faltar sob seus pés. Somente os entusiastas que possuem a coragem de suportar a dor da constante auto-crítica e que conseguiram superar a rejeição que o sistema estabelecido lhes impôs é que estarão autorizados a se juntar à equipe de trabalho que conduzirá este conhecimento aos novos horizontes que se descortinarão. E é por isso que existe a necessidade de elaborar um trabalho gigantesco para discernir e reavaliar o conceito individual, por um lado, e organizar esse conhecimento, de outro. Para agrupar esses 
resultados é indispensável uma operação conjunta de conhecimentos, ou seja, é indispensável mobilizar os pesquisadores de todas as áreas do conhecimento da Ásia Oriental. Hoje, temos estudos voltados para esse objetivo de renomados pesquisadores da China e da Coréia.

Assim, aqui cabe uma nova indagação: por que o embasamento do conhecimento existente no Japão moderno é diferente do da Europa? Para respondermos a essa pergunta, é necessário explicitar como o conhecimento tradicional da Ásia Oriental incorporou os conhecimentos europeus e em que medida os valores foram sendo modificados. Essa busca inicia-se com o estudo de cada conceito formador da conjuntura intelectual e o processo de transformação ocorrido no contato com o contexto histórico. Ao sintetizar os conceitos e a história, revelamos o dinamismo da reconstrução do sistema conceitual que denominamos "História do corpo conceptual" (gainen hensei shi 概念編成史). Diante disso, temos um novo desafio: o que se deve fazer para estudar esse dinamismo na prática?

\section{2. “Literatura Japonesa” (Nihon bungaku日本文学) - Particularidade desse conceito.}

O termo "literatura japonesa" foi publicamente empregado por Fukuchi Ôchi (18411906) oito anos após a Restauração Meiji num artigo intitulado: "É lamentável a incompletude da literatura japonesa" (Nihon bungakuno fushin o tanzu, 1875) publicado no jornal Diário de Tóquio (Tôkyô nichinichi shinbun). Apesar de o artigo não identificar a autoria, nota-se que o autor apreendeu o preciso significado com que o termo "literatura" estava sendo empregado em inglês e nas demais línguas européias naquela época. $O$ fato de o autor ter viajado inúmeras vezes à Europa desde o final do período xogunal, além de ser o administrador do jornal, nos permite apontar Fukuchi Ôchi como sendo o mais provável autor desse artigo. Ele lamenta a postura dos intelectuais da época que se limitavam a apresentar os conhecimentos da Europa e os adverte para voltarem a atenção ao Japão, ou melhor, às ciências humanas japonesas e, em particular, à grandeza de sua "arte do dizer literário" (gengo geijutsu言語芸術). Fukuchi Ôchi, fluente tanto em francês quanto em inglês, empregou o termo "literatura" (bungaku) no campo das humanidades que incluía as aulas de "exercícios literários" (sakubun kyôiku 作文教育) em língua japonesa. Ao fazê-lo, os escritos japoneses - os poemas (waka 和 歌), os romances (shôsetsu 小説) e o drama (gikyoku 戯曲) - passaram a ser denominados "Literatura Japonesa" (nihon bungaku日本文学) pela primeira vez².

2. Anterior ao artigo "É lamentável a incompletude literatura japonesa" (1875) de Fukuchi Ôchi, temos desde 1872 o emprego do termo "literatura" na Gazeta Oficial (Kanpô) no sentido de "Arte e Literatura dos poemas chineses e japoneses" (gakugei shiika). Em Breve história do florescimento do Japão (1877-1882), Taguchi Ukichi (1855-1905) emprega o termo "literatura" englobando os estudos confucionistas (jugaku) e os escritos populares em prosa (gesaku). N.T.: Gesaku são escritos populares em prosa de ficção na maioria cômica, que se desenvolveu notadamente no período Tokugawa. 
Enquanto a poesia chinesa (kanshi 漢詩) desde a Antiguidade era considerada um gênero da "literatura" (bungaku文学), as poesias japonesas (waka 和歌) e as narrativas (monogatari 物語) não o eram até o final do período Tokugawa e, portanto, não há nenhum registro de que fossem consideradas "literatura". Isso porque, até então, o termo "literatura" era empregado para designar todos os gêneros de obras clássicas (kanseki 漠籍) importadas da China ou, de modo restrito, para se referir aos estudos desses clássicos. Esse critério de uso do termo "literatura" era tão rígido que não há nenhuma exceção de emprego desse termo para se referir à poesia japonesa (waka) e às narrativas (monogakatari). Não havia, portanto, uma categoria correspondente ao conceito moderno de "literatura"3.

E é por isso que em seu artigo Fukuchi Ôchi afirma o quão lamentável é constatar que a História do Japão ainda não tenha sido escrita em japonês. A começar pelas Narrativas dos tempos áureos (Eiga monogatari 栄花物語, início do século XI, 1028; 1092) sobre o auge político da família Fujiwara e o Grande Espelho (Okagami 大鏡, provavelmente do início do século XII) e as demais narrativas Espelhos (kagami mono 鏡もの) 4", assim como As narrativas de Heike (Heike monogatari 平家物語, início do século XIII) e nas Narrativas da grande paz (Taiheiki 太平記, final do século XIV) foram excluídas do campo da História (rekishi 歴史) ${ }^{5}$. No entanto, não se pode afirmar que na época que Ôchi escreveu esse artigo ele tenha considerado as obras escritas em chinês tais como as Crônicas do Japão (Nihon shoki日本書紀, 720) e obras do tipo Registros do Japão (Honchô jitsuroku 本朝実 録) como sendo "literatura japonesa" (nihon bungaku). Isso porque, a partir do momento em que a "literatura" dos países europeus deixou de utilizar o latim, antes considerado língua padrão no Sagrado Império Romano, passou-se a se considerar "literatura" somente as obras escritas na língua nacional do país; Ôchi, possivelmente conhecendo esse fato, também deve ter considerado "literatura japonesa" somente as obras escritas em japonês.

Foi a partir do século XX que os estudiosos de literatura japonesa começaram a denominar esse conjunto de obras como "narrativas históricas" (rekishi monogatari 歴史 物語), mas os historiógrafos até hoje as definem como obras de história. Citamos como exemplo o caso das Narrativas da grande paz (Taiheiki), obra que narra a batalha ocorrida

3. Nakamura Yukihiko (1911-1998) em "Panorama da Literatura dos Confucionistas do período Pré-Moderno" In: História da Literatura Japonesa, volume 7, Tóquio, Editora Iwanami Shoten: 1958; classifica a arte literária do período Bunsei (1818-1830) inserindo-a nos juizos de valor "elegante e vulgar": "Literatura Elevada" (jô no bungaku) e "Literatura Vulgar" (ge no bungaku) e afirma que nesse período já existia o conceito de "literatura" (bungaku), mas isso é um erro advindo da imitação dos termos "Literatura Pura" (jun bungaku) e "Literatura Popular" (taishî bungaku) que foram empregados no pós-guerra. Depois, esse erro se estendeu aos pesquisadores da literatura do periodo moderno.

4. NT "Kagami mono" refere-se ao conjunto de "narrativas históricas" (rekishi monogatari) que possuem no título a palavra espelho (kagami): Imakagami (1170), Mizukagami (1170-1180) e Masukagami (1376).

5. No entanto, no catálogo da Biblioteca Central de Tóquio (no bairro de Ueno) e nas demais bibliotecas públicas, os "kagami mono" (narrativas dos "espelhos") e as narrativas militares fazem parte dos livros de História. 
no período medieva $1^{6}$, quando ocorreu a divisão da Corte imperial em Corte Norte e Corte Sul. No período Meiji, os estudiosos de história da Universidade Imperial (de Tóquio) questionaram essa versão que descreve o poderoso clã de Kusunoki Masashige (12941336) como partidário da Corte do Sul, o que acarretou a teoria da co-existência das cortes norte e sul. No entanto, mesmo tendo ocorrido a polêmica sobre a legitimidade dessas cortes em 1911, na qual se julgou legítima apenas a corte do sul, a narrativa continuou a ser utilizada como referência histórica. Os estudiosos da literatura japonesa também foram influenciados por esse ponto de vista, mas nem por isso revidaram essa opinião. No dicionário contemporâneo de literatura japonesa7, contudo, está escrito que: "a tragédia da batalha enfatizou a moral dos homens e seu valor é inestimável como uma literatura que revela o profundo lamento de um povo que enfrentou do início ao fim a acirrada competição dos imperadores pela supremacia política". Esta avaliação contradiz o que se apregoava antes da Segunda Guerra Mundial. Em outras palavras, antes da Segunda Guerra, as Narrativas da grande paz (Taiheiki) eram consideradas uma obra histórica e, mesmo após a guerra, os historiadores consideravam-nas como parte de seu acervo, mas entre os estudiosos de literatura esta obra, após a guerra, passou a ser considerada "literatura" (esta opinião é baseada no ponto de vista do autor deste artigo). Assim, quando se constitui o histórico crítico de uma obra clássica, como é o caso das Narrativas da grande paz (Taiheiki), devese começar por indagar se a obra deve ser lida como "história" ou como "literatura" Há, portanto, uma intrínseca relação com o gênero que se atribui a ela. $\mathrm{E}$, desnecessário dizer, há a importância de se questionar como se deu a relativização histórica da "formação do conceito" (gainen hensei 概念編成) de "literatura" (bungaku文学).

Por volta de 1890, iniciou-se a elaboração da História da Literatura Japonesa (Nihon bungakushi) e, via de regra, o levantamento parte de obras escritas no século VII, tais como o Relato de fatos antigos (Kojiki 古事記), Crônicas do Japão (Nihon shoki 日本書紀) e Registro das Particularidades Regionais (Fudoki風土記). Atualmente, mantém-se assim. O Relato de fatos antigos (Kojiki) é uma obra mitológica sobre os imperadores, as Crônicas do Japão (Nihon shoki) são uma mistura de mitologia e história e o Registro das Particularidades Regionais (Fudoki) é um livro de topografia. Essas obras foram incorporadas pela primeira vez como parte da Literatura Japonesa somente no início do período Meiji. Isso porque o Japão assimilou o conceito europeu de "História da Literatura" como veículo da expressão do nacionalismo, da consideração pela cultura nacional de cada um dos países europeus, e o remodelou para construir a "História da Literatura Japonesa" com o objetivo de agrupar o conjunto de obras escritas por diferentes camadas da sociedade e de regiões distintas, unificando-as como expressão da cultura

6. NT Período Medieval (final do século XII ao final do século XVI).

7. In: Grande Dicionário de Literatura Japonesa Edição Shinchô (Shinchô Nihon Bungaku Daïiten), editora Shinchô, 1968 e Dicionário de Literatura Japonesa Eediçâo Shinchồ (Shinchô Nihon Bungaku Jiten), 1988. 
do povo japonês. Nesse sentido, serviu como instrumento para a "invenção da tradição" (dentôno hatsumei 伝統の発明) ou instrumento de valorização da milenar história do Japão, mais do que propriamente para aceitar a poderosa influência ocidental. No entanto, há dois pontos básicos que diferenciam o tal conceito de história da literatura do adotado nos países europeus.

Em primeiro lugar, nota-se que, no Japão, a história literária é muito mais abrangente do que a área de Ciências Humanas na Europa. As Humanidades, na Europa, referem-se aos estudos das palavras dos homens em oposição à Palavra divina. Por isso, o departamento que se encarrega das áreas de humanidades numa universidade tradicional - hoje em dia há inúmeras denominações - separava o departamento de teologia do de literatura. Em contrapartida, a "literatura japonesa" engloba tanto as mitologias clássicas quanto as obras sobre xintoísmo, confucionismo e budismo. Isso, com base no modelo adotado na história da literatura européia, que ao reunir as concepções de nacionalismo e romantismo buscou inspiração na mitologia greco-romana e nas crenças em deuses e espíritos locais (os países nórdicos, por exemplo, buscaram inspiração na mitologia germânica), para incorporá-las nas obras literárias. Por isso, no Japão, não houve nenhuma resistência em incorporar as crenças religiosas como parte de sua "história da literatura" A despeito de ser - ou não a religião dominante na Europa, inclusive ignorando o fato de a religião ser considerada herética, o critério de incluir a coexistência de diversidades religiosas na Ásia Oriental estabeleceu-se como base para o desenvolvimento das humanidades, desde então.

$\mathrm{O}$ Relato de fatos antigos (Kojiki) foi escrito em ideogramas chineses, mas o texto já está bem próximo da língua japonesa; as Crônicas do Japão (Nihon shoki) foram escritas com base nos falares da região de Chang'an, capital de Tang daquela época. Os livros sobre os Registros das Particularidades Regionais (Fudoki) foram escritos em épocas e regiões diferentes, mas todos eles foram escritos em chinês. E em praticamente todas as tabelas cronológicas da história da literatura japonesa, as obras poéticas iniciam-se pelas coletâneas de poesia chinesa Kaifûsô (751) seguidas de outras obras escritas em chinês. Nesse sentido, a literatura japonesa pode ser considerada bilíngüe.

Esta é uma situação ímpar no mundo. Como já dissemos anteriormente, a história da literatura de cada país europeu é um produto do nacionalismo lingüístico e nela constam apenas as obras escritas em suas respectivas línguas.

8. Diversas circunstâncias são formadoras de nações constituídas com dois ou mais povos; no entanto, apesar de ser um país bilíngue ou trilíngue e elaborar uma única história da literatura nacional, o objeto principal de educação em cada território lingüístico restringe-se a obras escritas nessa língua. Por outro lado, podemos pensar numa História da Literatura sem considerar as fronteiras de um país, mas como países que falam a mesma língua, no caso, a língua francesa. No Império turco-otomano, que durante muitos anos esteve subjugado pelos árabes, denominou-se "Literatura árabe" a literatura pré-modernista e os escritos após a unificação dos povos e "Literatura egípcia" a literatura correspondente ao domínio imposto pelo colonizador. Em ambos os casos, não existe uma "História da Literatura" bilíngüe. A única exceção é o caso do Japão 
A "literatura japonesa" que possui essa característica e a "literatura japonesa" atual que considera a poesia (shi 詩), o romance (shôsetsu 小説) e o drama (gikyoku 戯曲) como “arte do dizer literário através das letras” (moji ni yoru gengo geijutsu文字による言語芸 術) é categoricamente distinta. Há, portanto, a necessidade de se questionar qual a relação existente entre a "literatura" no sentido mais amplo (kôgi 広義) e no sentido mais restrito (kyôgi 狭義) ${ }^{9}$ A partir do momento em que o sentido atual de "literatura" compreende a "arte do dizer literário através das letras", faz-se necessário entender as mudanças de sentido da palavra "arte" (geijutsu 芸術) desde o chinês clássico - onde havia concepções distintas de “arte" (gei 藝), das seis artes (rokugei 六藝) e das técnicas do "artístico" (jutsu 術) - até a atual concepção de “arte” (geijutsu 芸術).

\section{A releitura do termo geijutsu (芸術Artes) e o surgimento da terminologia bijutsu (美術 Belas Artes)}

Em Shôsetsu Shinzui (A essência do romance), o escritor Shôyô Tsubouchi classifica o romance japonês (shôsetsu 小説) como uma manifestação artística pertencente à área do Bijutsu (Belas Artes美術). A arte literária ou arte da palavra inclui-se no campo da Literatura ou das Humanidades e o seu significado varia dentro do âmbito do Geijutsu (Artes芸術) e do Bijutsu (Belas Artes美術). É necessário pensar nas ramificações semânticas desses termos e também na mudança dos seus conceitos. Os termos Geijutsu e Bijutsu possuem características distintas e mesmo os vocábulos ingleses art e fine art são polissêmicos, tendo cada um deles sentidos amplos, restritos e também o que chamamos "intermediários" Por isso, foi bastante sinuosa a trajetória percorrida pelos dois termos desde a sua utilização como meras traduções até receberem as acepções atuais.

A palavra yìshù ${ }^{10}$ (芸術) já existia na China. O dicionário etimológico chinês Cíyuán (1980, edição revista) fornece no verbete de 藝術"1 a seguinte explicação: "referese às técnicas em geral" Na crônica histórica Hòu Hán Ji (Livro da Dinastia Han Posterior) anotada por Fú Zhàn (?-37) indica-se que se refere a wứjīng (Cinco Clássicos五経), $z h \bar{u} z$ i $b$ ă ijiâ (Cem Escolas de Filosofia諸子百家), yìshù (Artes藝術) e na mesma obra anotada por Li Xián registram-se as palavras shú (Matemática数), shé (arco e fecha射), yù

que, influenciado pela China durante muitos séculos, escreveu textos em chinês, sendo que a linguagem do povo desenvolveu-se numa escrita peculiar conhecida como Man yôgana. O mesmo ocorreu na História da Literatura da Coréia que, além do chinês, também desenvolveu a escrita hangul, constituindo um bilingüismo. No entanto, no caso da Coréia, atualmente as obras chinesas passaram a ser desconsideradas.

9. Para uma leitura mais detalhada ver Suzuki, Sadami. O conceito de "literatura" no Japão (Nihon no bungaku gainen). Editora Sakuhinsha. 1998.

10. Para transliteração do chinês, utilizamos o sistema Hanyu Pinyin.

11. NT: o ideograma 藝 é a forma antiga de 芸. 
(carruagem御), bŭ (adivinhação卜) e shì (adivinhação筮). O termo yi (藝) é a denominação das Seis Artes Chinesas (Liùyì藝), ou seja, $l \grave{1}$ yuè shè yù shū shù (ritual-música-arco e flecha-carruagem- caligrafia-matemática 礼樂射御書数); a palavra shù (術) indica a arte médica e as mais variadas formas de adivinhação. A crônica traz como um exemplo de uso a expressão "Jin shũ yìshù chuán xù 晋書藝術伝序”

O termo yìshù (藝術) nasceu da junção das palavras representadas pelos ideogramas 藝 e 術 e sintetiza as práticas do homem e as suas técnicas em geral, equivalendo plenamente ao significado contido no vocábulo inglês art. Por isso, os termos yìshù (藝術) e art tornaramse equivalentes. Mas, em $L \grave{1} j i ̀$ (Livro dos Rituais), aparece anotado que $s h \overline{1}-s h \bar{u}-l \grave{1}-y u e ̀$ (poesia-caligrafia-ritual-música 詩書礼樂) são as Quatro Técnicas Chinesas (sìshù 四術), mostrando que a palavra shù (術) sozinha corresponderia ao conceito de art no sentido amplo. Na prática, porém, utilizava-se a palavra shù (術) com sentido restrito de "arte inferior", em oposição à yì (芸ou 藝) que se referia à arte de valor superior e nobre. As palavras yì ( 藝) e shù (術) possuíam significados muito diversos e desconheço o grau de frequência de uso da palavra composta yishù (藝術). Lembrando que era comum utilizar palavras de dois ideogramas para traduzir palavras européias, o sentido amplo de art não deveria ser shù (術) e sim um termo de maior extensão, representada pela junção de yì (芸ou 藝) e de shù (術).

No epitáfio de Shôzan Sakuma (1811-1864), neo-confucionista ortodoxo japonês e estudioso das "coisas" holandesas do fim do período Edo, além de pioneiro do pensamento filosófico europeu do período Meiji, há uma inscrição com a expressão "Seiyô geijutsu, tôyô dôtoku (西洋芸術、東洋道徳)" que significa que o Ocidente supera em tecnologia (representada pela palavra geijutsu芸術) e o Oriente, em moral (dôtoku 道徳).

Resta, no entanto, a dúvida de quando a palavra art foi traduzida para yishì (芸 術). No dicionário inglês-chinês Lobscheid (Hongkong, 1866), o verbete de art dá como equivalentes chineses: shŏuyì (arte manual 手藝), jìy (habilidade 技藝), yìyè (atividade 藝 業), shìyè (carreira事業), jìshù (técnica 技術), jiliăng (destreza 技倆) e gōngyì (arte工 藝); e, como exemplo de seu uso, "the six liberal or polite arts" referindo-se às citadas Seis Artes chinesas (Liùyì 六藝); e, como equivalente de "literary exercises". é fornecida a palavra chinesa wènyì (文藝); para "skill" jīqiăo (機巧).

A expressão liberal arts tem sua origem em termo helênico, que significava a educação dos homens livres da Grécia antiga, passando a denotar as disciplinas que compunham a educação média e superior da Idade Média européia, ou seja, o trivium (gramática, retórica e lógica) e o quadrivium (aritmética, geometria, astronomia e música), chamadas de Sete Artes Liberais. Na época moderna, passou a significar Conhecimentos Gerais (em inglês, liberal arts). Foi considerando essa acepção que liberal arts foi traduzido para Seis Artes (六藝 Liùyi) que, na China, referia-se aos conhecimentos e às boas maneiras a serem adquiridos pela elite. 
Por outro lado, a expressão literary exercises dizia respeito às práticas de redação. O termo wènyi (文藝) deve ter sido criado pela junção da idéia de 藝 (técnica) e 文 (texto). Tradicionalmente, significava tanto "técnica de texto" quanto "texto e técnica", sendo sinônimo de wènxué (texto文 estudo学) - "texto e estudo" ou "estudo de texto"-; dizia-se também yì̀è (藝文). Como ambos os termos indicavam arte nobre, o uso sofreu considerável desvio. Sobrepondo-se ao significado contido em rhetoric, o termo wènyi (文 藝) era uma das acepções de wènxué (文学), como foi anteriormente discutido.

No verbete de fine do citado dicionário inglês-chinês Lobschied (1866), a expressão "the fine art" foi traduzida para Liùyì (Seis Artes 六㙯), outra denominação para Liùjīng (Seis Clássicos六経), e referia-se a $l \grave{1}-y u \grave{e}-s h \grave{e}-y \grave{u}-s h \mathrm{u}-s h \grave{u}$ (ritual-músicaarco/flecha-carruagem-caligrafia-matemática 礼楽射御書数), para fazê-las corresponder às disciplinas abrangidas pela locução "the fine arts" Essa equivalência não nos parece apropriada. Entretanto, a expressão inglesa "the fine art" pode indicar também os estudos superiores, subtraindo-se tecnology ou engineering, que são atividades realizadas pelas mãos de artesãos e operários. Tal é o sentido amplo e equivalente a "liberal arts" Acreditamos que foi por essa razão que o termo Liùyì (Seis Artes 六藝) aparece exemplificado no verbete de fine.

No sentido que estamos denominando 'intermediário', fine art refere-se às artes em geral como as entendemos hoje, tais como literatura, artes plásticas e música; mas, no sentido restrito, indica as artes plásticas representadas pela pintura e escultura. Assim, art tem as seguintes acepções, em ordem decrescente de alcance semântico: de tecnologia em geral desenvolvida pelo Homem, de fine art no sentido amplo, de fine art no sentido intermediário e, por fim, no sentido restrito de fine art.

Vamos ao termo 美術 (chinês: měishùç; japonês: bijutsu). Não o encontramos no já citado dicionário etimológico chinês Ciyuan. É, portanto, um neologismo criado na época moderna. No Grande Dicionário de Chinês (Hànyǔcí dà cìdiăn, 1986-94) encontra-se a explicação de que a palavra měishùç (美術) começou a ser utilizada na época do Movimento Quatro de Maio (1919). De fato, na década de 1920 publicou-se a revista Arte chinesa contemporânea (Zhōngguó xiàndài měishùç 中国現代美術) que possui o termo 美術 no título, utilizado na acepção atual de artes e artes plásticas. O crítico japonês de arte, Noriaki Kitazawa, informou que a palavra bijutsu (japonês: 美術) apareceu no Japão pela primeira vez no decreto do Departamento de Estado do governo Meiji, de janeiro de 1873, cujo texto era um incentivo à participação na Exposição Universal de Viena. O crítico explica ${ }^{12}$ que o termo bijutsu (美術) era uma tradução do alemão "Kunstgewerbe" ou “Bildende Kunst",

12. Ver Kitazawa, Noriaki. Me no shinden (Templo dos olhos). Editora Bijutsu shuppansha, 1989, capítulo 2, parte 3 “美術Bijutsu no kigen - hon'yakugo bijutsu no tanjô (Origem do termo bijutsu - nascimento da palavra traduzida bijutsu)" 
acrescido do sentido de "Schöne Kunst" A palavra deu nome a uma escola de desenho industrial implantada pelo Ministério da Indústria, chamada Kôbu bijutsu gakkô 部美術学 校 em 1976, entrando, assim, para o vocabulário de uso geral ${ }^{13}$.

É inegável a importância dada ao Kôgei (Arte Artesanal 工芸) na primeira metade do período Meiji, como uma das estratégias de crescimento da economia. Mas, então, como se generalizou a idéia de separar Kôgei de Bijutsu (Belas Artes美術), esta com forte conotação de artes plásticas? Deve-se pensar que havia outra corrente de tradução e criação do termo bijutsu, distinta daquela originada do alemão.

Do fim do período Edo até o início do período Meiji, os intelectuais japoneses absorveram a forma de produção do saber ocidental através dos estudos sobre a Inglaterra e os EUA. Os estudiosos das 'coisas' holandesas também migraram para essa nova área. Houve maciça importação de livros ingleses traduzidos para o chinês e os próprios japoneses passaram a ler a bibliografia no original inglês. Nesse contexto, o termo bijutsu (美術) provavelmente foi utilizado com o sentido de artes em geral, tais como música, pintura, escultura, poesia, etc., ou seja, no significado dito intermediário de fine art.

No capítulo das considerações gerais da enciclopédia Hyakugaku Renkan, Amane Nishi, filósofo de tradição ocidental atuante no início do período Meiji, traduz os termos science and arts para gakujutsu-gigei (学術技芸); a locução mechanical art para gijutsu ( 技術), e a expressão liberal art para geijutsu (芸術) ${ }^{14}$. Estabelece Aesthetics como sub-área da Filosofia e cria o termo japonês Kashuron (佳趣論, sentido literal: ciência do gosto elegante $)^{15}$ como seu equivalente. Lembro, no entanto, que essa informação encontra-se numa reunião de anotações dos seus alunos e que foi publicada somente após a Segunda Guerra Mundial.

O texto "Bi'myôgakusetsu (Teorias sobre Estética)" parece ter sido escrito pelo próprio Nishi para uma palestra dirigida ao imperador, por volta de 1877 . Nele, Nishi traduz esthetic (hoje, bigaku) para bi'myôgaku, e discorre sobre a sensação do agradáveldesagradável livre de interesses, sobre os efeitos da imaginação, entre outros temas. Fine art é utilizado no seu sentido dito intermediário e traduzido ${ }^{16}$ com significado de bijutsu (Belas Artes 美術) e artes em geral. Num outro texto, “Meiji Bungaku Kaisha Sôshi no Hôhô (Método de criação de uma associação da literatura do Meiji)", para uma conferência na Academia Japonesa, em 1879, Nishi cria o termo bijutsukan (美術館) para se referir à

\footnotetext{
13. Ver Kitazawa, Noriaki. "Formação do conceito de bijutsu"

14. Nishi Amane Zenshû (Obras Completas de Amane Nishi), Vol. 4, editora Shokô, 1962.

15. Idem, p. 146.

16. Idem ibidem, p.15.
} 
Académie des Beaux Arts $^{17}$, lembrando que a citada academia lidava somente com pintura e escultura.

Foi o método de ensino dessa Académie des Beaux Arts que criticou Eugène Véron no seu livro L'Esthétique (1878), traduzido por Chômin Nakae e publicado pelo Ministério da Educação Japonesa com o título Yuishi bigaku (Teoria da Estética de E. Véron], 1884-85. Elegendo como formas de arte a pintura, a escultura, a poesia, a música e a dança, Véron pregou a importância de o escritor expressar a individualidade, o sentimento e a nacionalidade; criticou a interferência do academicismo sobre a liberdade do artista; afastou a cópia pura e simples das obras clássicas, explicando ser essencial que o artista, ao reproduzir a realidade, imprimisse a sua personalidade e o seu sentimento à obra. Trata-se de explanações acerca dos métodos do Realismo pautados nas idéias do Romantismo.

Antes, Ernest Francisco Fenollosa (1853-1908), estrangeiro contratado para lecionar filosofia na Universidade Imperial de Tóquio, proferira uma conferência (logo traduzida e publicada com o título Bijutsu Shinsetsu (Verdadeira teoria sobre Artes), em 1882 , na qual apresentou a moderna teoria sobre artes. Nessa fala ${ }^{18}$, Fenollosa inclui música, poesia, pintura e caligrafia, escultura e dança como manifestações das artes, com destaque para a música, poesia e pintura, os quais, discorre, buscariam o Belo; e, posteriormente, expõe sobre as técnicas de pintura. Fenollosa critica a tendência realista da pintura a óleo, enfatizando que a obra artística é o resultado de 'fazer' do homem e que obra e artista formam uma unidade.

Fenollosa e Véron concordavam que a finalidade da arte era a busca do Belo, mas tinham opiniões contrárias quanto ao Realismo. Ambos excluíram a arquitetura da arte, que, por sinal, já dava mostras de autonomia da fine art em meados do século XIX, devido à sua praticidade.

Autoridade em pesquisas sobre a literatura do período Meiji, Izumi Yanagida (1894-1969) afirma que "é provável que a poética japonesa passasse a fazer parte do Bijutsu (Belas Artes 美術) nos anos de 1882 ou $1883^{19}$ ” Percebe-se que, diferentemente da palavra bijutsu originada do alemão "Kunstgewerbe", difundia-se, na segunda metade da década de 1880 , o seu uso com o sentido atual, com significado intermediário de fine art, a partir de outra fonte, como a citada conferência de Fenollosa. Foi com esse segundo sentido que o escritor Shôyô Tsubouchi o teria utilizado, nas considerações sobre o fato de o romance

17. Nishi Amane Zenshû (Obras Completas de Amane Nishi) Vol. 2, editora Shokô, 1962, p.585.

18. Meiji Bungaku Zenshû (Literatura do Periodo Meiji), vol 79. Op.cit., 1975, p.37.

19. Yanagida, Izumi. Meiji shoki no bungaku shisô (Idéias literárias do inicio do periodo Meiji), Vol. 2, editora Shunshûsha, 1965, p.50. 
japonês (shôsetsu) ser uma manifestação do Bijutsu (Belas Artes 美術), no seu texto Shôsetsu Shinzui (A essência do romance).

Questiono se, naquela época, a idéia de que o termo bijutsu (美術), denotando Artes em Geral, não estaria ainda limitada ao uso de especialistas, ou seja, ao grupo de intelectuais da área de Humanidades. Geralmente um termo científico surge em revistas especializadas e se expande para revistas de assuntos gerais; os jornais tendem a utilizar determinado termo, não pela sua precisão, mas visando uma fácil compreensão pelo leitor comum. Os dicionários registram-no quando o termo se fixa numa determinada comunidade de fala.

Na edição de 1884 do dicionário inglês-chinês Lobscheid, revista e ampliada por Tetsuji Inoue, o verbete de art está mais simplificado do que o da edição de 1866; o verbete de fine, por sua vez, traz "the fine art" como sendo liùyì (Seis Artes六蕘), sishù (Quatro Técnica四術) e jìyì (habilidade 技藝). Está ausente a palavra měishù (美術). A palavra jìyì (技㙯) é um termo chinês antigo, usada normalmente como yì (芸) e shù (術), ou seja, no sentido amplo de art em geral, não sendo apropriada como tradução de "the fine art"

É a edição de 1897 do dicionário inglês-chinês de Lobschied, publicado em Yokohama, que traz o exemplo de "the fine art" como sendo equivalente de měishù (美術),

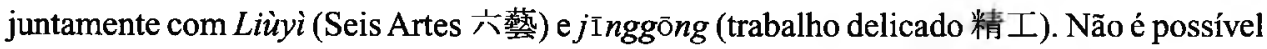
uma afirmação conclusiva, mas provavelmente a palavra měishù (美術), com significado de Artes em geral, tenha se fixado nesse período. O dicionário Pŭtong Shúyŭ Cíhui (Léxico de palavras compostas comuns, 1905) traz no verbete de yishi (芸術) exemplos do uso tradicional como sentido lato; no sentido intermediário diz ser "o comumente conhecido měishù (美術 [fine art])" e, no sentido estrito, traz exemplos limitados à pintura e à escultura. O “comumente conhecido měishù (美術)" corresponde às Artes em Geral, que se fixa durante a passagem para o século XX.

O crítico Noriaki Kitazawa afirmou ${ }^{20}$ que a Exposição de Artes do Ministério da Educação/Cultura de 1907 foi o marco para que o termo bijutsu (美術) passasse a indicar somente pintura e escultura e que essa tendência à restrição aparece literalmente na parte das "Ressalvas" no verbete de bijutsu (美術) no dicionário Jirin (1911). O Bungaku Shingo Shôjiten (Pequeno Dicionário de Neologismos Literários, 1913) registra ${ }^{21}$ que o termo bijutsu (美術) passou a indicar restritivamente pintura e escultura, permitindo-nos afirmar que esse uso limitado passou a ocorrer na década de 1910.

Por outro lado, é possível encontrar a expressão jun bungaku (純文学 literatura pura) até pelo menos em 1911, apesar de o termo bungaku (文学 literatura), com o sentido

20. Ver Kitazawa, Noriaki. Me no shinden (Templo dos olhos). Op.cit., p.299.

21. Ver o verbete芸術 (Geijutsu (Artes) no Kotoba Konceputo Jiten (Dicionário de Conceitos). Editora Daiichi hôki shuppan, 1992. 
de arte da palavra escrita, circulasse entre os jovens intelectuais, muito provavelmente devido à distinção feita com as disciplinas Filosofia (Tetsugaku) e História (Shigaku) durante a reforma da Faculdade de Cultura da Universidade Imperial de Tóquio, em 1904, como dissemos anteriormente. Além disso, aumenta o uso de outro termo, Bungei (文芸), com o significado de "arte do texto/palavra" Ocorrendo ao mesmo tempo que a restrição de Bijutsu (美術) à pintura e escultura, ou seja, às artes visuais ou plásticas, trata-se de um mecanicismo ${ }^{22}$ no qual se consolida a oposição entre a "arte da palavra" (Bungaku ou Bungei), de um lado, e as artes de apelo visual, ou Bijutsu (美術), de outro.

Desta maneira, mesmo com a coexistência dos termos jun bungaku, bungei e bungaku, observa-se que o conceito de "arte da palavra escrita" fixa-se socialmente no período entre a guerra russo-japonesa (1904-1905) e o ano de 1910. Esse fato é possível de ser verificado pela própria mudança de significado da palavra bundan (文壇, antes, um círculo amplo de intelectuais incluindo políticos) que passou a indicar, após a guerra russo-japonesa, em especial após 1910, o restrito círculo literário, ou seja, um grupo de especialistas ligados a Bungaku.

Geijutsu (Artes), Shûkyô (Religião) e Tetsugaku (Filosofia) são termos cujo conceito foi reconstruído no Japão do período Meiji, após re-significação da terminologia tradicional. Estritamente, a palavra Rekishi (História) também passou pelo mesmo processo ${ }^{23}$. Acreditamos que seja desatando esse emaranhado, atendo-se às relações conceituais e ao lugar e valor de tais conceitos, ou seja, ao processo de sua reconstrução, que será possível transpor os limites das pesquisas anteriores e partir para novas investigações completamente inovadoras em Artes e Cultura.

\section{A ideologia por detrás de um estilo - Formação do "estilo unificado da linguagem escrita e oral" (genbun itchi 言文一致) e o "retrato da paisagem com sentimento" (jôkei 情景)}

A principal corrente de pesquisa e de crítica no pós-guerra tinha como objetivo estabelecer estratégias para reiniciar o processo de modernização do Japão promovendo-o nos moldes do que vinha ocorrendo na Europa Ocidental. Esta postura, durante algum tempo, provocou certa confusão nas linhas de pesquisa sobre a "História da Literatura Japonesa" (bungakushi 文学史). Isso fica evidente com as polêmicas ocorridas no período

22. No livro Gainen (Conceito), tratamos resumidamente dos termos e respectivos conceitos de geijutsu (芸術 Artes) e bijutsu (美術 Belas Artes), não esclarecendo esse ponto.

23. Para o conceito de Rekishi (歴史 [História]), ver meu artigo "Nihon ni okeru rekishi no rekishi (A história da História no Japão)" em Nihon Kenkyû (Pesquisas sobre o Japão), no. 35, março de 2007. 
Meiji que tratavam do "estilo unificado da linguagem escrita e oral" (genbun itchi 言文 一致) e da questão da "cópia" (shasei写生; writing sketches) dos conceitos ocidentais. Os fundamentos que norteavam essas duas questões eram equivocados por não levarem em consideração as diferenças culturais. Também pressupunham que o contexto europeu também estaria se refletindo no Japão moderno ou que, caso assim não fosse, o mesmo deveria acontecer, mas, infelizmente, isso não ocorreu. Não se pode dizer que, mesmo hoje, não exista mais esse tipo de equívoco.

A "reforma para a utilização da língua coloquial na escrita" (zokugo kakumei俗 語革命) ocorrida na Europa tinha como fundamento padronizar a língua latina - antes considerada uma língua padrão entre os letrados do Sagrado Império Romano - com base na linguagem falada utilizada pelo povo e, também, o de elaborar uma gramática normativa e descritiva das línguas escrita e falada na língua nacional de cada país. Mas, para que isso se concretizasse, por mais que já houvesse um esboço para tal padronização, seria necessário pelo menos um século e meio ou mais para sua completa realização. Além do que haveria a necessidade de se ignorar a questão da retórica, que possuía uma longa e profunda raiz histórica relacionada à oratória que deveria vir acompanhada de estratégias inovadoras de criação de um "estilo transparente" (tômei na buntai透明な文体) que permitisse a expressão direta dos pensamentos do autor como um estilo autêntico de expressão de sua individualidade.

Em contrapartida, no Japão, desde muito tempo havia grupos de letrados capacitados tanto na leitura quanto na escrita do chinês - espalhados por todo o território e, por conta disso, as circunstâncias encontradas foram bem adversas das do Ocidente. Para esses letrados, conhecedores de ideogramas, foi tarefa fácil transcrever os sons da língua japonesa falada (yamato kotobaヤマトヨトバ) por meio da transcrição fonética “man'yôgana”(万葉 仮名) que adequava o som da fala à leitura do ideograma. No entanto, essa adequação exigiu esforços contínuos para que se estabelecesse o processo de sistematização dos ideogramas em leituras japonesas (kunjutsu訓述), a desconstrução da frase chinesa para a seqüência frasal japonesa e as estratégias para construção de modelos que permitissem ler em japonês a frase chinesa como se fosse texto escrito na língua japonesa. Do período medieval ao moderno, houve um aumento significativo de textos que incorporavam a língua falada nos sermões budistas e nos textos confucionistas e, com a expansão das capacidades de leitura e escrita, grande parte da população passou a escrever textos cujas frases terminavam em nome ou verbos na forma infinitiva (taigen ya iikiri shûshikei体言や言い切り終止形), sem a preocupação de empregar uma retórica específica. Entre a intelligentsia (chishikisô 知識層), escrever um texto de "estilo transparente" era uma tarefa fácil, assim como o era escrever em estilo personalizado. Um bom exemplo desse estilo transparente são os romances de Ihara Saikaku. 
Assim sendo, no Japão do período Meiji não havia como ocorrer uma "reforma para a utilização da língua coloquial na escrita" (zokugo kakumei) semelhante ao que ocorreu na Europa. A proposta de se estabelecer um "estilo unificado da linguagem escrita e oral" (genbun itchi) no período Meiji estava relacionada à questão de eliminar a métrica 7-5, assim como evitar o uso de antíteses e certas figuras de linguagem como os encontrados em textos chineses adaptados ao japonês ${ }^{24}$. Buscava, também, a padronização de certo estilo de escrita, especialmente das formas utilizadas em finais de frase, para evitar o uso da forma abreviada, comumente encontrada nos textos escritos pelas massas. Além disso, havia somente 20 anos que a forma terminativa $d a$ (verbo ser e estar; escrita informal) e dearu (verbo ser, estar; escrita formal) tinham se fixado como estilo padrão a ser empregado nos textos editados pela intelligentsia.

Apesar disso, após a Segunda Guerra Mundial, surgiu entre os estudiosos de língua e literatura e os críticos de arte uma teoria que defendia a idéia de que a polêmica sobre o "estilo unificado da linguagem escrita e oral" (genbun itchi) no período Meiji fora algo semelhante ao da "reforma para a utilização da língua coloquial na escrita" (zokugo kakumei) ocorrida na Europa. Até hoje, essa teoria é aceita. Há de se ressaltar que essa teoria tem apenas sentido estritamente conceitual.

À parte, surgiu nova teoria que defendia a idéia de que a manifestação do realismo só ocorreu objetivamente no Japão, em parte, devido à influência dessa teoria anterior. $\mathrm{Na}$ China do século VI essa técnica da "cópia da vida" (shasei写生; writing sketches), que procurava ser o mais fidedigna possível ao objeto copiado, era denominada "imitação" (shôkei象形) e, desde então, existia um modelo padrão que servia de treinamento ao ato de desenhar. Na Dinastia Sung (960-1279), esse termo passou a designar os trabalhos que retratavam diretamente os seres vivos. $\mathrm{E}$, em decorrência desse objetivo de retratar fielmente o objeto, desenvolveu-se a "técnica de apagamento do contorno" (bokkotsu byôhô没骨描 法) para ser condizente à inexistência de contornos nos objetos reais. Desenvolveram-se também, no século XI, técnicas de representação que possibilitavam a "ilusão de perspectiva" (enkinkan遠近感) com o emprego do ponto de vista aéreo (fukan 'hô俯㒈法) e da técnica de gradação das sombras (in'eihố陰影法). A essa técnica de retratar fielmente a paisagem denominou-se "cena real" (shinkei真景). Nesse sentido, a "pintura de montanha e rios" (sansuiga 山水画) desenvolvida na Dinastia Sung padronizou um modelo de representação da "energia vital" $(k i$ 気). E como essa tradição era do conhecimento dos pintores do período Tokugawa, há de se convir que nesse período houvesse a distinção entre a técnica da "cópia

24. Comumente, lia-se diretamente o texto em chinês e o termo "leitura japonesa do texto chinês" (kundokutai) não é condizente. No período Edo, para as traduções de poemas, textos e romances chineses já estavam estabelecidas normas detalhadas de como fazer a adaptação do texto chinês para o japonês no sentido literal do termo "leitura japonesa do texto chinês" (kundokutai). 
da vida" (shasei 写生), que copiava o objeto, e a "cena mental" (shai 写意), que retratava as cenas imaginadas por alguém em seu pensamento ${ }^{25}$.

$\mathrm{Na}$ Europa, somente com a introdução de temas da mitologia greco-romana é que se deixou de promover as pinturas religiosas que retratavam o mundo conceitual do cristianismo. Foi no período renascentista que estratégias para conseguir o efeito de perspectiva alcançaram êxito com a utilização de composições geométricas por meio de técnicas desenvolvidas através de aparelhos ópticos. É opinião corrente que essa tendência acompanhava a formação ideológica do homem moderno de controlar o mundo através de seu ponto de vista subjetivo. Se bem que haja pinturas religiosas que também adotaram essa técnica. Essa linha que privilegiava a técnica da perspectiva também foi utilizada no século XVIII pelos pintores do período Edo, dentre os quais destacamos Maruyama Ôkyo (1733-1795) que estudou as técnicas da perspectiva e a utilizou conjuntamente com a técnica do sombreado que, mais tarde, no início do século XIX, foi utilizada pelos pintores regionais (chihô eshit地方絵師). Quanto a Katsushika Hokusai (1760-1849), desenvolveu várias tendências através de uma utilização livre seja de composições com a técnica da perspectiva de múltiplos pontos de fuga, seja de ênfase em elementos da paisagem representados em grande dimensões, numa espécie de anti-perspectiva (gyaku enkinkan逆遠近感), desenvolvendo inúmeras possibilidades de expressão ${ }^{26}$. As pinturas de Hokusai agradaram os pintores europeus de fins do século XIX que queriam se libertar das amarras ilusionistas da técnica da perspectiva.

As questões artísticas surgidas a partir de meados do século XIX na pintura européia eram as de tornar a pintura uma expressão fiel da "impressão" (inshố印象) que o objeto causava no observador. Para alcançar esse objetivo, o conhecimento dos estudos ópticos (kôgaku no chishiki光学の知識) aliou-se a estratégias tais como o pontilhismo (tenbyôho点描法) e foi a partir do século XX que o método de pintura em perspectiva foi sendo abandonado.

No que tange ao estilo narrativo, foi na segunda metade do século XIX que textos descritivos que relatam as mudanças ocorridas nas paisagens e que falam de "impressões" (inshô印象) sobre a passar do tempo começam a surgir, como por exemplo o "Diário

25. Na China, o Confucionismo era uma doutrina filosófica dominante da elite, mas entre o povo existiu um

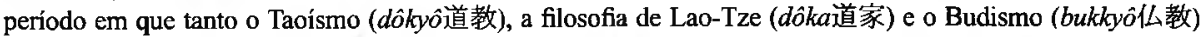
eram concomitantes. O Neoconfucionismo (shushigaku朱子学) só se infiltrou nas massas após a dinastia Sung (960-1279). No Japão, existia o sincretismo religioso do Xintoismo (shintố 神道), Confucionismo (jukyón儒教) e o Budismo (bukkyố(亿教) e, por conseguinte, não existiu a supremacia de uma religião que fosse considerada dominante. No período Tokugawa, propagou-se ainda o Secularismo (genseshugi現世主義).

26. A técnica da perspectiva foi comumente adotada nas construções de edifícios e nos desenhos de ambientes intemos, mas em paisagens naturais era necessária grande destreza na construção do sombreado e dos matizes de cores. Atualmente há teorias que reconhecem a influência da pintura chinesa na Europa. Com a divulgação da fotografia a partir de meados do século XIX, os pintores passam a utilizar a técnica da tridimensionalidade na pintura, inspirados pela observação da paisagem através das lentes. 
do Caçador" (Zapski okhotnika, 1852), de Ivan Sergeevich Turgenev (1818-1883). Essa tendência observada na pintura relaciona-se à "reforma para a utilização da língua coloquial na escrita" (zokugo kakumei) na medida em que procura eliminar os recursos retóricos de embelezamento da frase (bunshoku文飾). Na virada do século XX, o que foi introduzido no Japão seja na pintura, seja na prosa, foi a reprodução dessas "impressões" (inshô) relacionadas com a transitoriedade do tempo.

Futabatei Shimei (1864-1909), após estudar o Realismo da Rússia, traduziu o Diário do Caçador (Karyûdo Nikki, 1888), de Turgenev, utilizando em abundância o verbo em sua forma aspectual perfectiva $t a{ }^{27}$, para descrever as transformações gradativas observadas pelo narrador. (No entanto, no final seu texto foi reescrito na forma consagrada nari e tari). Kunikida Doppo (1871-1908), ao tomar conhecimento do significado dos esboços de cenas externas que Nakamura Fusetsu (1866-1943) aprendera com a pintura impressionista francesa, motivou-se em representar as transformações das paisagens naturais ("Musashino, de hoje" 1898) e incentivou Tokutomi Roka (1868-1927) a fazer o mesmo. Masaoka Shiki (1867-1902), responsável pela "renovação do haiku" (haiku kakushin俳句革新) também foi influenciado por Fusetsu e, tendo como lema o impressionismo, propõe uma "descrição objetiva dos eventos" (jojibun叙事文1899) na prosa.

Assim como ocorreu o movimento de ressurgimento da busca da técnica de retratar a "impressão" (inshô印象) nas pinturas ocidentalizadas dos japoneses que assimilaram a corrente impressionista francesa no texto, em vez de "paisagem", igualmente surgiu o movimento de ressurgimento da "impressão" (inshô印象) relatada nos textos. Essa técnica se distanciou dos conceitos previsíveis e atentou para o conhecimento das sensações e de sua conscientização, num processo semelhante ao ocorrido mais tarde nos estudos da fenomenologia ${ }^{28}$. No entanto, há de se convir que o texto não é uma pintura. Nem, tampouco, filosofia. Ele também difere do poema haiku. Basta lembrarmos a coletânea de "cópias", uma espécie de esboços (sketch) realizados por Roka, "Cinco minutos dedicados à Natureza" (Shizen ni taisuru gofunji自然に対する五分時, 1899). Tanto Doppo quanto Roka registraram suas "impressões" sobre uma determinada cena em transformação.

27. O auxiliar verbal tempo aspectual $t a$ (tempo passado; aspecto perfectivo) era utilizado na linguagem falada e, portanto, seu emprego era restrito a citaçōes e diálogos entre personagens. Na parte descritiva do texto, o emprego era do auxiliar verbal tempo aspectual tari. Havia uma nítida distinção de uso dessas partículas. (Nota do Tradutor)

28. Inoue Tetsujirô, em "Filosofia do século XIX" In: Revista Taiyô (太陽), edição especial sobre estudos do século XIX (1900) tece comentários sobre as tendências atuais da Filosofia Ocidental. No entanto, na época em que o autor redigiu esse artigo, ele interpretou que o mecanicismo (kikairon機械論) e o materialismo (yuibutsuron唯物論) foram correntes novas que surgiram com a decadência da filosofia conceptualista (gainenrontetsugaku概念論哲学). Este tipo de confusão se perpetuou por cerca de 10 anos, concomitante à fixação dos conceitos de "sensação感覚" e "impressão印象" 
$\mathrm{Na}$ Ásia Ocidental, durante a dinastia Qing (1616-1912), surgiu na poesia uma proposta de distanciamento dos modelos retóricos. Como dissemos anteriormente, no Japão isso já ocorria desde o período Tokugawa. $\mathrm{O}$ texto que resgatava a "impressão" em detrimento do embelezamento e da retórica tradicional, valorizando as sensações que a paisagem descortinada aos olhos provocava, significava que poderia ser escrito em chinês ou no estilo chinês com leitura japonesa. Isto significa que a prática não tinha nenhuma relação com a polêmica sobre 0 "estilo unificado da linguagem escrita e oral" (genbun itchi) ocorrida no período Meiji.

O objetivo principal de Doppo e Roka não era, portanto, o de descrever suas "impressões" sobre as mudanças percebidas. Na verdade, o objetivo deles era o de registrar a emoção no instante do contato com a "vida" (seimei生命) existente na Natureza. No caso de Shiki, equivale ao que ele dizia ser o encontro com os "Segredos da Criação" (zôka no himitsu造化の秘密). Tendo como suporte esse tipo de conceito, referiam-se às observações das paisagens em transformação e o sentimento que geravam no autor. Isso não se restringia ao mundo subjetivo nem à observação objetiva da "paisagem" (fûkei風景) ou do "cenário" (kôkei 光景), mas à junção de tudo isso no ato de "retratar a paisagem com sentimento" (jôkei情景).

Se isso for de dificil compreensão, basta pensar no sentimento de "refrescância" (sukazukashiiすがすがしい) ao entrar em contato com o ar da montanha. Essa impressão de "refrescância" não se sabe ao certo se é um atributo do ar da montanha ou se é algo imanente à percepção da pessoa envolvida. Basta pensar num caso assim e logo se chegará à conclusão de que não há como descobrir qual dessas opções é a correta.

Segundo o estudioso de filosofia do século XX Nishida Kitarô (1870-1945), em Sobre a Existência (Jitsuzai ni tsuite実在に就いて,1907) e, mais tarde, no volume 2 "Existência" (Jitsuzai 実在) em Pesquisas sobre a virtude (Zen no kenkyû善の研究, 1911), ao conhecer a obra de William James (1842-1910) intitulada Mundo das Experiências Genuinas (Junsui keiken no sekai 純粋経験の世界,1904), explicitou que essa situação era como uma "síntese do subjetivo e do objetivo" (shukaku gôitsu主格合一). Tempos depois, Takamura Kôtarô (1883-1956) explica em "Sol verde" (Midori iro no taiyốn緑色 の太陽,1910) que, se o Sol for visto como verde, pode-se perfeitamente pintá-lo de verde. Sugestionados por esses autores, Mushanokôji Saneatsu (1885-1976) em Para si mesmo (Jiko no tame自己の為) e Público e eu (Kôshû to yoto公望と予と), ambos de 1912, considerou que esse estado de conscientização que se uniu ao objeto era a "subjetividade" pós-corrente naturalista. Por outro lado, na Europa, especialmente na Alemanha, surge a "Estética da Empatia" (kanjô inyû bigaku感情移入美学; Einfühlung) baseada no Idealismo - que apregoa que só se aceita o que é belo quando se introduz o subjetivo no objetivo - e ocorre também um movimento que incentiva a expressão dos sentimentos e da atmosfera que a paisagem produz na pessoa. Essa concepção será seguida por Abe Jirô (1883-1959) que buscava um novo conceito de filosofia. 
No entanto, as principais correntes da crítica de arte do pós-guerra apontaram essa formação artística calcada em descrições objetivas como integrante das características modernistas e, ainda, relacionaram-na ao movimento de "estilo unificado da linguagem escrita e oral" (genbun itchi). Em decorrência disso, essa polêmica lingüística girou em torno de intensas polêmicas teóricas totalmente distanciadas de seu contexto histórico. Nakamura Mitsuo (1911-1988), em Romances japoneses modernos (Nihon no kindai shôsetsu日本 の近代小説 1954) aponta Tsubouchi Shôyô (1859-1935) e Futabatei Shimei (1864-1909) como sendo os precursores do romance moderno, ou seja, os responsáveis pela inclusão do modelo realista de cunho objetivo. Contrariando essa informação, o crítico Etô Jun (19331959), em seu ensaio A Origem do Realismo: Problemas em prosa e outros (Riarizumuno genry $\hat{u}$ - shaseibun to tashano mondai, リアリズムの源流 写生文と他者の問題1971) refuta que esses autores acima citados sejam os precursores do realismo moderno no Japão e aponta Masaoka Shiki (1867-1902) como o precursor desse movimento. Isso com base no livro de Shiki, intitulado Descrição objetiva dos eventos (Jojitsubun 叙事文 1899), que apresenta a representação do "texto-cópia da Vida" (shaseibun). A teoria de Etô afasta-se da crítica baseada no mundo conceitual e fundamenta essa tendência modernista à formação de um ideário realista do tipo fotográfico (shashinteki riarizumu写真的リアリズム). Mas isso não significa que ele não percebeu que a fotografia, ou mesmo a coisa real, não destituíam as conotações conceituais (kyôdô gainen共同概念). Para ilustrar tal fato, temos como exemplo as pessoas que aparecem no mundo das Narrativas de Genji (Genji monogatari). Mesmo que alguém tenha conhecido a mulher chamada Yûgao, na narrativa esse fato é tratado como simbólico ou como um tipo de código do personagem. Para explicar de outro modo esse tipo de convenção existente é que Karatani Kôjin (1941) escreveu As Origens da Literatura Moderna Japonesa (Nihon kindai bungakuno kigen, 1980). Karatani incorpora a dualidade subjetivo e objetivo do Renascimento que se desenvolveu independente da concepção cristã e reconhece nos textos de Doppo (1871-1908) o estilo "paisagem" (fûkei), ou seja, o estilo descritivo-objetivo distanciado do ponto de vista subjetivo de estrutura bem definida. E, em particular, no período Edo, difunde-se também o Secularismo (genseshugi 現世主義) e, com isso, a oposição "subjetivo" (shukan主観) e “objetivo" (kyakkan客観) passa a ser considerada natural e, por conseguinte, até mesmo a coexistência de modelos tais como o da "cópia" (shasei 写生) e o da "cena real" (shinke $i$ 真景) foi ignorada e a técnica de perspectiva (enkinhồ遠近法) e seus "pontos de fuga" (shôshitsuten消失点) tornaram-se anacrônicos no contexto histórico cultural ${ }^{29}$ Todas essas teorias acabaram sendo relacionadas como simultâneas à ocorrência do realismo objetivo e do movimento de "estilo unificado da linguagem escrita e oral" (genbun itchi).

29. Sugerimos a leitura de "Conceitos" (Gainen), capitulo X. 
Logo, o que significou a polêmica do "estilo unificado da linguagem escrita e oral" (genbun itchi) ocorrida no período Meiji? O "estilo unificado da linguagem escrita e oral" (genbun itchi) foi um movimento para adaptar a língua que era falada pelo povo desde o período Edo, classificando morfologicamente as estruturas frasais comumente utilizadas com finalização em substantivos (taigen dome) em substantivos pró-forma koto e verbos e adjetivos na forma infinitiva (yôgen dome). Ou seja, este movimento estava diretamente relacionado a uma sistematização da língua falada em escrita a partir da regulamentação das finalizações frasais, isso porque, para o povo, que não conhecia os textos chineses clássicos lidos em japonês, as formas $d a$ e dearu tinham surgido havia muito tempo, mas essas formas só foram incorporadas, de fato, nos textos escritos pelos eruditos após a guerra russo-japonesa, na época em que essa tendência se manifestava também nos romances ${ }^{30}$.

\section{Releitura da história das idéias da arte moderna e contemporânea - libertação dos paradigmas do Realismo}

A tarefa de esclarecer as especificidades do sistema de produção intelectual que se construiu no Japão entre a segunda metade do século XIX e a primeira do XX não se destina a apontar o seu atraso ou distorção na Ásia, segundo o paradigma moderno criado na Europa ou nos EUA. Ao contrário, trata-se de relativizar as peculiaridades do sistema europeu/norte-americano, de acompanhar o seu desenvolvimento e contribuir para uma reorganização de todo o sistema que ofereça perspectivas futuras.

O pensamento japonês, alinhado com a ocidentalização-modernização e tendo como indicador o Realismo objetivo - seja na expressão das teorias do Estilo Unificado da Língua Falada e Escrita, seja na da Teoria Literária da Cópia da Vida - caiu em anacronismo. Para se apreender a verdadeira forma de expressão japonesa do período que se inicia na primeira metade do século XX, é preciso se colocar numa perspectiva internacional e atentar para o fato de que, na transição para o século XX, a arte européia e norte-americana adotava o Simbolismo e, o Japão, estimulado por esse movimento, buscava formas próprias de transformação.

O Realismo, entendido como valorização da experiência, está presente, na verdade, na antiga tradição da Ásia Oriental. A percepção de que o mundo é regido por leis objetivas, livres do subjetivismo do observador, construiu-se no interior do pensamento neo-confucionista da dinastia Song (960-1279), o qual estava enraizado

30. Sugerimos a leitura de "Estilo unificado da linguagem escrita e oral (genbun itchi) e a técnica de "cópia da vida" (shasei)" In: Revista Língua e Literatura Japonesa (Kokugo to kokubungaku, 2005/2006). 
entre os intelectuais do período Edo e na população em geral, embora fosse na forma adaptada ao modo japonês. Quando as expressões criadas no século XIX europeu, desde o Positivismo ao Naturalismo, alcançaram o mundo artístico japonês, tais correntes estavam ficando ultrapassadas no continente de origem. Além disso, o próprio Naturalismo europeu tinha várias facetas - seja na expressão de um Guy de Maupassant, que apresenta a verdade nua e crua de uma cena da vida mesclada à ficção, seja na de um Ibsen, que em Casa de Bonecas (1879) revela a hipocrisia da sociedade burguesa - e caminhava para o Simbolismo, voltado para os mistérios da natureza. Se compreendido dentro dessa dinâmica, o Naturalismo introduzido no Japão não teria se subdividido em tantas teorias e opiniões quanto o número de críticos e escritores existentes. $\mathrm{E}$, nesse emaranhado, preparava-se também o caminho para a escola simbolista que, se na França, na Inglaterra ou na Alemanha assumia características próprias, era natural que no Japão apresentasse outras transformações devido à forma particular de construção de conceitos.

O modo como o Japão incorporou o Simbolismo europeu provocou grande mudança na apreciação das "coisas" clássicas. Houve incentivo ao estudo da Nova Coletânea de Poemas do Passado e do Presente (Shin Kokin Wakashû), praticamente esquecido até então, e passou-se a valorizar os haicais de Bashô sob a ótica das idéias artísticas modernas. Esse poeta em particular tornou-se a expressão dos poetas simbolistas e, em meados da década de 1920, Haruo Sato, representante da literatura do período Taishô, transformou-o num símbolo da libertação das artes literárias modernas no artigo “Teoria da elegância na graciosidade", Fûryûron, de 1924. Outro proeminente escritor da segunda fase da literatura do período Taishô, Sakutarô Hagiwara, propagou os haicais de Bashô "como poemas simbolistas japoneses que coroam o mundo", no artigo "Essência do Símbolo" (Shôchô no honshitsu, 1926). Acrescente-se que o campo de Estudos Literários Japoneses, fundamentados na Estética da Sensação (Einführung), e também o Curso de Estética da Universidade Imperial de Tóquio elegeram wabi, sabi e yûgen (simplicidade, quietude, refinamento) como valores estéticos representativos do período medieval japonês (séculos XII a XVI), os quais foram difundidos, em meados da década de 1930, como principais características do que depois seria chamado de "o mais típico do Japão"

Após a Segunda Guerra Mundial, essa visão contagiou as artes da cerimônia do chá e do teatro nô e, no auge do nacionalismo cultural que vigorou no período anterior $\mathrm{e}$ posterior às Olimpíadas de Tóquio (1964), a expressão "wabi, sabi, yûgen (simplicidade, quietude, refinamento)" foi largamente difundida no exterior como sendo uma peculiaridade do Japão. Isso significou a invenção e a expansão de uma tradição distinta daquela que esteve associada à formação da cultura nacional do período Meiji. 


\section{Conclusão}

Tanto as teorias do Estilo Unificado das Línguas Falada e Escrita quanto a Teoria Literária da Cópia da Vida são resultado da modernização do pós-guerra ou de sua extensão e também estão presas a um esquema chamado Ocidentalização/Modernização. Além disso, indicam a insuficiência do antagonismo binário que o opõe ao Tradicionalismo, sendo possível propor um esquema substitutivo de análise da cultura do período Meiji, no qual se cruzam, num quadrante, o eixo da Ocidentalização versus Japonismo/'Asianismo' e o da Modernização versus Conservadorismo da Tradição. Isso é, entretanto, apenas um esquema e não é possível colocar, em nenhum quadrante, a grande corrente chamada Modernização baseada no aperfeiçoamento (Ocidentalização) da Tradição encontrada em diferentes áreas da cultura do período Meiji. Lembre-se também que o esquema perde a sua eficácia já na época logo após a Guerra Russo-Japonesa, quando cresce a ideologia de que Ocidente e Oriente se harmonizam ou se fundem ${ }^{31}$

O esquema da Ocidentalização/Modernização baseia-se sobre a re-modernização que aconteceu no pós-guerra. Enquanto a modernização julgou o pensamento tradicional como sendo cultura antiga e ultrapassada - utilizou-se muitas vezes a palavra $h$ ken (feudal) - e enquanto a análise girou em torno do esquema de alternância do novo e do antigo, não houve fundamentalmente mudança de ponto de vista que reconhecesse o valor da tradição e a intenção de perceber como conflituosos o novo e o antigo. Generalizando, não se constituiu uma estrutura em que a recepção/transformação de um pensamento novo e a releitura/reavaliação da tradição evoluíssem interligadas.

Sendo assim, torna-se imprescindível elucidar o processo em que a tradição se transforma com a incorporação de conceitos e idéias novas, e também como estes causam uma revalorização da tradição e atualizam a percepção do que é tradicional. Em outras palavras, é preciso apresentar um arranjo no qual o vanguardismo da época propicie, concomitantemente, a reavaliação do que é clássico e a reinvenção da tradição ${ }^{32}$.

31. Ver Suzuki, Sadami. Nihon no bunka nashionarismu (O nacionalismo cultural do Japão). Editora Heibonsha shinsho, 2005.

32. "Invenção da tradição" é uma forma de interpretação da História desenvolvida por historiadores da Universidade de Cambridge que se aliaram a pesquisadores de Antropologia Cultural e ampliaram o campo de investigação, antes focado em política e economia, para a cultura do cotidiano. Refere-se às intenções de se transformar em tradição algum costume novo e, portanto, não tradicional, na tentativa de se afirmar dentro do contexto de formação do homem e do estado nacional moderno. Alguns exemplos: o kilt (saia em tecido xadrez dos escoceses) não é um vestuário milenar tradicional, mas sim invenção de um costureiro londrino do século XIX; os rituais de várias tribos africanas foram reelaborados, acrescidos de maior esplendor, para recepcionar governadores de paises colonizadores, como o Império Inglês; buscou-se uma origem antiga para o Primeiro de Maio que fosse apropriada como Dia do Trabalho (em Hobsbaum, Eric \& Lenger, Terence. Invention of Tradition. 1968). Influenciados por essa nova visão de História, sociólogos japoneses apontaram 
O vanguardismo na literatura e a reapreciação do clássico sempre caminharam juntos, inovando a Literatura Japonesa como um todo. Essa tendência persistiu ao longo do século $\mathrm{XX}$. Acreditamos que só conscientes das tendências internacionais e também desse esquema seja possível uma grande reinterpretação da história literária e cultural do Japão.

(Tradução de Eliza Atsuko Tashiro Perez e Shirlei Lica Ichisato Hashimoto)

para o fato de que alguns rituais xintoístas, como hatsumôde (Visita ao Santuário no Ano Novo) e cerimônias matrimoniais nessa religião, foram criados no período Meiji. Em relação a isso, assinalei que o próprio termo "tradição", que antes significava um conjunto de costumes antigos transmitido numa linhagem monárquica ou em determinada família, passou a denotar, no Ocidente moderno, a continuidade dos costumes de um povo ou comunidade desde a antiguidade, observando que esse processo foi semelhante no Japão ou na China. $O$ método de análise foi estendido para compreender a constituição do conceito de tradição no período moderno, sendo aplicado à releitura da história do sistema imperial moderno, da literatura japonesa, etc. Lembro, entretanto, que tal processo no Japão já tinha sido observado por Tarô Okamoto (ver "Dentôron no atarashii tenkai (Desdobramentos da teoria da tradição)", em Nihon no dentô ( $A$ tradição no Japão). Kadokawa bunkoban, 1964). Sobre isso, ver "Introdução" do Wabi, sabi, yûgen (simplicidade, quietude, refinamento) e o capítulo 10-3 de Tankyû (Pesquisa). O escritor e crítico Nyozekan Hasegawa, em Kokuminteki seikaku to shite no nihon seishin ( $O$ espirito japonês como uma caracteristica nacional, 1935), explorou a relação cultural pacífica do Japão com a China na antiguidade, afirmando que a compilação de Kojiki (Relatos dos Fatos Antigos) deveu-se ao espírito renascentista nascido como reação do desenvolvimento cultural da China. Hasegawa assinalou, ainda, que o mesmo sentimento fez retomar, no período Meiji, o espírito contido em Jinnô shôtôki (Crônica sobre a legitimidade da Casa Imperial, 1338-1341), de Chikafusa Kitabatake, nobre e pensador do período medieval japonês (séculos XII a XVI), e que o "Japão puro" ressurge ciclicamente, sugerindo que essa repetida "invenção da tradição" seja uma das especificidades da cultura japonesa. Tratase de uma acertada análise da sua cultura. Veja-se Wabi sabi yûgen (Simplicidade, quietude, refinamento), op.cit., p. 37 e Tankŷu (Pesquisa), op.cit., p.618. 